\title{
Changes in physiological and antioxidant activity of indica rice seedlings in response to mannitol-induced osmotic stress
}

Sutee Chutipaijit ${ }^{1^{*}}$

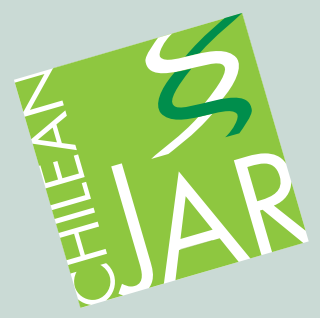

\section{ABSTRACT}

Morphological, physiological, and biochemical plant responses were studied in unstressed and stressed seedlings of indica rice (Oryza sativa L.) genotypes. The effect of NB medium supplemented with a $100 \mathrm{mM}$ mannitol treatment, which induced drought stress conditions, was measured for relative growth rate, cell membrane stability, antioxidant enzyme activity (superoxide dismutase [SOD], catalase [CAT], and peroxidase [POD]), and total antioxidant capacity by DPPH (2,2-diphenyl-1-picrylhydrazyl) and ABTS (2,2'-azinobis[3-ethylbenzothiazoline-6-sulfonic acid] diammonium salt) assays. Results of morphological and physiological factors showed two contrasting rice groups, drought-sensitive and drought-tolerant genotypes. After drought stress, the increased rate of SOD activity was lower in drought-tolerant than in drought-sensitive genotypes, but the increased rate of CAT and POD activity and total antioxidant capacity was higher in drought-tolerant than in drought-sensitive genotypes. Increasing changes in activity levels of antioxidant enzymes and total antioxidant capacity indicated more rapid free radical scavenging compared with relative growth and cell membrane stability in drought-tolerant genotypes under shortterm treatment. The trend toward change in CAT and POD antioxidant enzyme activity and total antioxidant capacity of stressed seedlings, as well as the correlation between these changes, and the morphological and physiological responses ( 0.96 correlation coefficient $\left[\mathrm{R}^{2}\right]$ between relative growth rate and CAT; $0.93 \mathrm{R}^{2}$ between relative growth rate and POD enzyme activity; $0.96 \mathrm{R}^{2}$ between relative growth rate and Trolox equivalent antioxidant capacity values) coincided with the degree of drought tolerance.

Key words: ABTS, antioxidant enzyme, DPPH, drought, Oryza sativa, rice.

${ }^{1}$ King Mongkut's Institute of Technology Ladkrabang, College of Nanotechnolog, Chalongkrung Rd. Ladkrabang, Bangkok, Thailand. "Corresponding author (natadee24@hotmail.com)

Received: 25 May 2016

Accepted: 12 September 2016.

doi:10.4067/S0718-58392016000400009

\section{INTRODUCTION}

Abiotic stresses, such as drought or water deficit, are the most important factors negatively affecting growth, production, and various physiological/biochemical plant processes worldwide (Cheng et al., 2013). Under drought stress, plants have a limited capacity to fix $\mathrm{C}$. This condition restricts $\mathrm{CO}_{2}$ assimilation due to stomatal closure that extends surplus electron flux to $\mathrm{O}_{2}$ and overproduction of reactive oxygen species (ROS). In addition, hydrogen peroxide $\left(\mathrm{H}_{2} \mathrm{O}_{2}\right)$ production is activated via the glycolate oxidase pathway during drought stress (Zhou et al., 2009). Therefore, drought conditions induce oxidative stress in plant cells. The ROS can damage chlorophyll pigments, proteins, DNA, and lipid membranes leading to cell death (Simova-Stoilova et al., 2008).

To protect themselves from this toxic condition, plants maintain a balance between ROS generation and consumption, which is strictly managed by the antioxidant defense system. This system is the accumulation of enzymatic and non-enzymatic components that defend cell membranes and other substances (Liu et al., 2013). Superoxide dismutase (SOD), catalase (CAT), and peroxidase (POD) are enzymatic components which play a central role in the defense system. The SOD decomposes superoxide radicals $\left(\mathrm{O}_{2}{ }^{-}\right)$to $\mathrm{H}_{2} \mathrm{O}_{2}$ by catalyzing the dismutation of the superoxide anion radical. The POD and CAT then reduce $\mathrm{H}_{2} \mathrm{O}_{2}$ to water using various substrates as electron donors (CarrascoRíos and Pinto, 2014). Rapid detoxification of $\mathrm{O}_{2}{ }^{-}$and $\mathrm{H}_{2} \mathrm{O}_{2}$ is essential to protect free radical damage in plant response.

The antioxidant metabolism is one of the plant metabolic pathways that can affect abiotic stress tolerance. The alteration and amount in antioxidant enzyme activity reveals a significant difference between plant species. Currently, numerous researchers have proven that plant stress tolerance is correlated with antioxidant enzyme activity, and they suggest an important tolerance mechanism to drought stress (Jaleel et al., 2009; Hameed et al., 2011). Rapid accumulation and maintenance of a high level of antioxidant enzyme activity can be a better protection mechanism under drought stress in plant cells. A correlation between the degree of drought stress tolerance and level of antioxidant enzyme activity was demonstrated in several plant species (Uzilday et al., 2012).

Rice (Oryza sativa L.) is a widely cultivated crop and one of the major staple foods for more than half of the world's population, and it provides approximately $30 \%$ to $40 \%$ of the calories consumed in Asia. These results are from a genetic and molecular study model in monocot plants. Rice is considered as 
one of the cultivated species that is highly sensitive to water deprivation, and it is also one of the most water intensive for production yield. World rice production in the future will be reduced by approximately $50 \%$ due to drought (Shukla et al., 2012). Various mechanisms and behavioral responses to drought stress are complex and have different patterns in each plant species. Therefore, knowledge and understanding of morphological, physiological, and biochemical responses in drought-tolerant and drought-sensitive rice are required to reduce production loss (Fu et al., 2011).

The present study investigated the relative growth rate of seven indica rice genotypes under drought conditions induced by $100 \mathrm{mM}$ mannitol. According to the relative growth rate and cell membrane stability, degrees of drought tolerance were selected in each rice genotype. The present study was also conducted to examine the pattern of antioxidant enzyme activity (superoxide dismutase, catalase, and peroxidase) and total antioxidant activity (ABTS and DPPH assays) on drought stress and associate the role of these enzymes in decreasing oxidative stress damage with the growth rate and cell membrane stability due to drought stress in sensitive and tolerant genotypes of indica rice seedlings.

\section{MATERIALS AND METHODS}

\section{Plant materials and stress conditions}

Seeds of seven rice (Oryza sativa L.) genotypes 'Khao Dawk Mali 105' (KDML105), 'Sangyod' (SY), 'Khaodang' (KD), 'Rice Department 15' (RD15), 'Klumsakolnakorn' (KS), 'Klumkhonkaen' (KK), and 'Pathumthani 1' (PT1) were dehusked and surface sterilized with $70 \%(\mathrm{v} / \mathrm{v})$ ethanol for $2 \mathrm{~min}$ followed by $5 \%(\mathrm{v} / \mathrm{v})$ commercial bleach $(5.25 \%$ sodium hypochlorite) for $40 \mathrm{~min}$ and $30 \%$ (v/v) commercial bleach $(5.25 \%)$ for $30 \mathrm{~min}$. Seeds were thoroughly rinsed six times in sterilized distilled water. Sterilized seeds were blot dried with sterilized tissue paper and aseptically cultured in NB medium (a medium combining $\mathrm{N}_{6}$ macroelement, $\mathrm{B}_{5}$ microelement, and $\mathrm{B}_{5}$ vitamin components; Li et al., 1993) and supplemented with $30 \mathrm{~g} \mathrm{~L}^{-1}$ sucrose and $8 \mathrm{~g} \mathrm{~L}^{-1}$ agar. Cultures were grown at $25 \pm 2{ }^{\circ} \mathrm{C}, 80 \pm 5 \% \mathrm{RH}$, and $60 \pm 5 \mu \mathrm{mol}$ $\mathrm{m}^{-2} \mathrm{~s}^{-1}$ photosynthetic proton flux density (PPFD) with a 16:8 h photoperiod provided by fluorescent lamps. After $7 \mathrm{~d}$ incubation, seedlings were germinated under photoautotrophic conditions using vermiculite as supporting material for $7 \mathrm{~d}$. These conditions were applied to NB sugar-free liquid medium and the number of air exchanges was adjusted to $2.32 \mathrm{~h}^{-1}$ with $\mathrm{CO}_{2}$ as a $\mathrm{C}$ source by punching a hole in the chamber $(\varnothing 1 \mathrm{~cm})$ and covering the hole with a microporous filter $(0.20 \mu \mathrm{m}$ pore size; Nihon Millipore, Tokyo, Japan) and grown at $25 \pm 2{ }^{\circ} \mathrm{C}, 80 \pm 5 \% \mathrm{RH}$, and $60 \pm 5 \mu \mathrm{mol} \mathrm{m} \mathrm{m}^{-2} \mathrm{~s}^{-1}$ PPFD with a 16:8 h photoperiod provided by fluorescent lamps. For drought stress exposure, seedlings were grown in NB sugar-free liquid medium supplemented with 0 or $100 \mathrm{mM}$ mannitol for 2 and $4 \mathrm{~d}$ under the previously described conditions. Subsequently, the unstressed and stressed seedlings were immediately collected and stored at $-80{ }^{\circ} \mathrm{C}$ prior to analysis.

\section{Growth measurements}

The unstressed and stressed seedlings were randomly selected to estimate growth by the relative growth rate (RGR) assay following the method by Noggle and Friz (1976). Dry weight (DW) was determined by drying samples in an aerated oven at $70{ }^{\circ} \mathrm{C}$ for $72 \mathrm{~h}$ and calculating the increase in DW by the equation $R G R=\left(\ln D W_{f}\right.$ $\left.\ln D W_{i}\right) /\left(T_{f}-T_{i}\right)$ where $D W$ is dry weight, $t$ is time, and subscripts denote the initial ( $0 \mathrm{~d})$ and final (2 and $4 \mathrm{~d}$ ) measurements of the unstressed and stressed treatments.

\section{Cell membrane stability assay}

Cell membrane stability (CMS) was measured following the method by Yan et al. (1996). Samples were cut into 1-cm pieces and then kept in a capped vial containing $10 \mathrm{~mL}$ of deionized water and incubated in the dark for $3 \mathrm{~h}$ at $30{ }^{\circ} \mathrm{C}$. Electrical conductivity (EC) was measured with a conductivity meter (Acorn series CON 6, Oakton Instruments, Vernon Hills, Illinois, USA). After the first measurement, vials were boiled for $2 \mathrm{~min}$ to release the electrolytes. Solutions were then cooled to $25 \pm 2{ }^{\circ} \mathrm{C}$ room temperature and the second EC measurement was taken. The CMS was calculated as a measurement of ion leakage from EC data.

\section{Enzyme extraction and antioxidant enzyme assays}

The unstressed and stressed seedlings were crushed into a powder in a mortar with pestle with liquid nitrogen. The crude enzyme of the powder was extracted in $50 \mathrm{mM}$ chilled sodium phosphate buffer $(\mathrm{pH} 7.8)$ and $1 \%(\mathrm{w} / \mathrm{v})$ polyvinylpolypyrrolidone (PVPP) at $4{ }^{\circ} \mathrm{C}$. The homogenate was centrifuged at $12000 \mathrm{~g}$ at $4{ }^{\circ} \mathrm{C}$ for $15 \mathrm{~min}$. In the supernatant, SOD, CAT, and POD enzyme activity was immediately determined.

The SOD enzyme activity was estimated according to Beauchamp and Fridovich (1971). The reaction mixture contained $390 \mathrm{mM}$ methionine, $2.25 \mathrm{mM}$ nitrotetrazolium blue chloride (NBT), $3 \mathrm{mM}$ EDTA, $1.5 \mathrm{M} \mathrm{Na}_{2} \mathrm{CO}_{3}$, and 150 $\mu \mathrm{L}$ crude enzyme extract. The reaction $\mathrm{pH}$ was adjusted to 10.2 and it was initiated by adding $1 \mathrm{~mL} 60 \mu \mathrm{M}$ riboflavin. The solution was placed below a light source of $18 \mathrm{~W}$ fluorescent lamps for $10 \mathrm{~min}$. Absorbance was recorded at $560 \mathrm{~nm}$ with a UV-visible spectrophotometer (Model Bio Mate 3, Thermo Electron, Waltham, Massachusetts, USA). The quantity of SOD generated the $50 \%$ reduction of NBT in the reaction and was defined as one unit of enzyme activity. Specific enzyme activity was expressed as units per milligram of protein.

The CAT enzyme activity was estimated according to Aebi (1984). The reaction mixture contained $19 \mathrm{mM} \mathrm{H}_{2} \mathrm{O}_{2}$ and $50 \mathrm{mM}$ sodium phosphate buffer $(\mathrm{pH} \mathrm{7.0)}$. It was initiated by adding $200 \mu \mathrm{L}$ crude enzyme extract to the 
reaction buffer solution. The reaction mixture was incubated for $30 \mathrm{~s}$ at $25 \pm 2{ }^{\circ} \mathrm{C}$ room temperature. Absorbance was recorded at $240 \mathrm{~nm}$ with a $\mathrm{UV}$-visible spectrophotometer. The decomposition of $\mathrm{H}_{2} \mathrm{O}_{2}$ was determined after absorbance decreased at $240 \mathrm{~nm}$. Activity was calculated as the $\mathrm{H}_{2} \mathrm{O}_{2}$ extinction coefficient of $36 \mu \mathrm{M}^{-1} \mathrm{~cm}^{-1}$ and expressed as $\mu \mathrm{mol} \mathrm{H}_{2} \mathrm{O}_{2} \mathrm{mg}^{-1}$ protein.

The POD enzyme activity was estimated according to Beffa et al. (1990). The reaction mixture contained $0.1 \mathrm{M}$ sodium phosphate buffer ( $\mathrm{pH} 6.0), 9 \mathrm{mM}$ guaiacol, and 2 $\mathrm{mM} \mathrm{H} \mathrm{O}_{2}$. The reaction was started by adding $50 \mu \mathrm{L}$ crude enzyme extract. Absorbance was measured at $460 \mathrm{~nm}$ with a UV-visible spectrophotometer. Activity was calculated as the $\mathrm{H}_{2} \mathrm{O}_{2}$ extinction coefficient of $6.39 \mu \mathrm{M}^{-1} \mathrm{~cm}^{-1}$ and expressed as $\mu \mathrm{mol} \mathrm{H}_{2} \mathrm{O}_{2} \mathrm{mg}^{-1}$ protein.

Total protein was assayed according to the Bradford (1976) method using bovine serum albumin as a standard.

\section{Total antioxidant capacity assays (DPPH and ABTS radical scavenging capacity)}

The unstressed and stressed seedlings (1 g) were ground in a mortar with pestle with liquid nitrogen. The fresh powder was used for antioxidant extraction with $4 \mathrm{~mL}$ of $60 \%(\mathrm{v} / \mathrm{v})$ acidic methanol (methanol: $\mathrm{HCl} ; 99: 1)$ at $25 \pm 2{ }^{\circ} \mathrm{C}$ room temperature for $2 \mathrm{~h}$. After extraction, the chlorophyll was removed with chloroform at $25 \pm 2{ }^{\circ} \mathrm{C}$ room temperature and centrifuged at $10000 \mathrm{rpm}$ at $4{ }^{\circ} \mathrm{C}$ for $10 \mathrm{~min}$. The supernatant solution was used to determine the total antioxidant capacity assay.

The DPPH (2,2-diphenyl-1-picrylhydrazyl) radical scavenging capacity was determined according to BrandWilliams et al. (1995). The $0.8 \mathrm{mM} \mathrm{DPPH}^{\bullet}$ solution in $95 \%(\mathrm{v} / \mathrm{v})$ methanol was prepared daily. A total of $150 \mu \mathrm{L}$ of this solution was mixed with $0-150 \mu \mathrm{L}$ plant extracts $\left(250 \mathrm{mg} \mathrm{mL}^{-1}\right)$ and the volume was adjusted to $1.5 \mathrm{~mL}$ by adding $95 \%$ (v/v) methanol. Samples were mixed and incubated in the dark at room temperature for $30 \mathrm{~min}$. After incubation, absorbance was detected at $517 \mathrm{~nm}$ with a UV-visible spectrophotometer. The level of $\mathrm{DPPH}^{\circ}$ remaining from each reaction was calculated as the percentage of inhibition (\% inhibition) and expressed as half of the maximal effective concentration $\left(\mathrm{EC}_{50}\right)$. The $\mathrm{EC}_{50}$ parameter, which reflects $50 \%$ depletion of the DPPH free radicals, was expressed as $\mu \mathrm{L}$ plant extract $\mathrm{g}^{-1} \mathrm{FW}$.

The ABTS (2,2'-azino-bis[3-ethylbenzothiazoline-6sulfonic acid] diammonium salt) radical scavenging capacity was determined according to Re et al. (1999). The ABTS radical cation $\left(\mathrm{ABTS}^{+\bullet}\right)$ solution was produced by a reaction between $7 \mathrm{mM}$ ABTS solution and $2.45 \mathrm{mM}$ potassium persulfate. The reaction mixture was incubated in the dark at room temperature for 12-16 h before use. The ABTS ${ }^{+}$ solution was diluted with ethanol to an absorbance of $0.7 \pm$ 0.02 at $734 \mathrm{~nm}$. For the initial assay, $1 \mathrm{~mL}$ diluted $\mathrm{ABTS}^{+\bullet}$ solution and $10 \mu \mathrm{L}$ plant extract were mixed and measured spectrophotometrically at $734 \mathrm{~nm}$ until the reaction reached a plateau. These measurements were compared to a Trolox standard curve, Total antioxidant capacity was expressed as the $\mu \mathrm{M}$ Trolox equivalent antioxidant capacity (TEAC).

\section{Statistical analysis}

Results were shown as mean values \pm standard deviation (SD) of five independent experiments $(n=5)$ and arranged in a completely randomized design. The data for various parameters were analyzed by the $t$-test and Duncan's multiple range test $(P \leq 0.05)$ (SPSS software package, SPSS for Windows, V. 11.0; IBM, Armonk, New York, USA).

\section{RESULTS}

The growth of unstressed and stressed seedlings in seven rice genotypes, estimated as the relative growth rate, was affected by $100 \mathrm{mM}$ mannitol in the NB medium. The second and fourth days after initiating the drought treatment, the relative growth rate decreased between $7 \%$ and $80 \%$ in stressed seedlings of all the rice genotypes compared with the control plants when exposed to $100 \mathrm{mM}$ mannitol (Figure 1). The RD15, KS, and KK genotypes maintained a high relative growth rate under drought stress and also showed lower reduction percentages ( $7 \%$ to $23 \%$ ) as compared with the KDML105, SY, KD, and PT1 genotypes (63\% to $80 \%$ ).

Cell membrane stability, estimated as electrolyte leakage, decreased under drought stress in all the genotypes (Figure $2)$. The RD15, KS, and KK genotypes showed a slight decrease in cell membrane stability $(6.50 \%$ to $10.50 \%)$ whereas the decrease in the KDML105, SY, KD, and PT1

Figure 1. Relative growth rate of unstressed and stressed seedlings of indica rice grown in a photoautotrophic system under drought stress (100 mM mannitol).

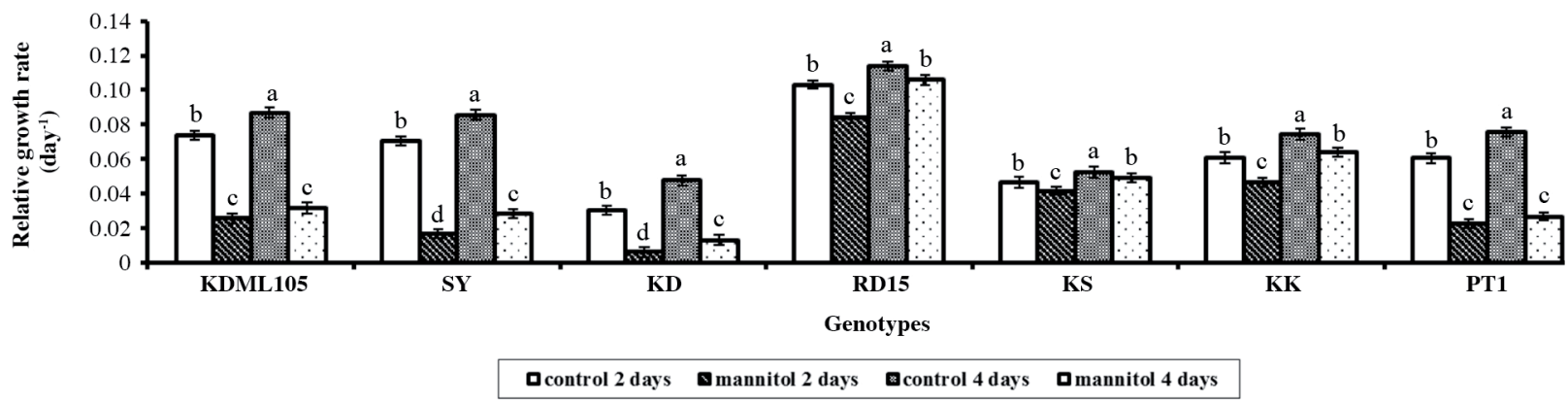

Values are means $\pm \mathrm{SD}$

Different letters for the same genotype are significantly different $(P \leq 0.05)$. 
Figure 2. Cell membrane stability of stressed seedlings grown in a photoautotrophic system under drought stress $(100 \mathrm{mM}$ mannitol) for 2 and $4 \mathrm{~d}$ compared to control treatment ( $0 \mathrm{mM}$ mannitol) set as $100 \%$.

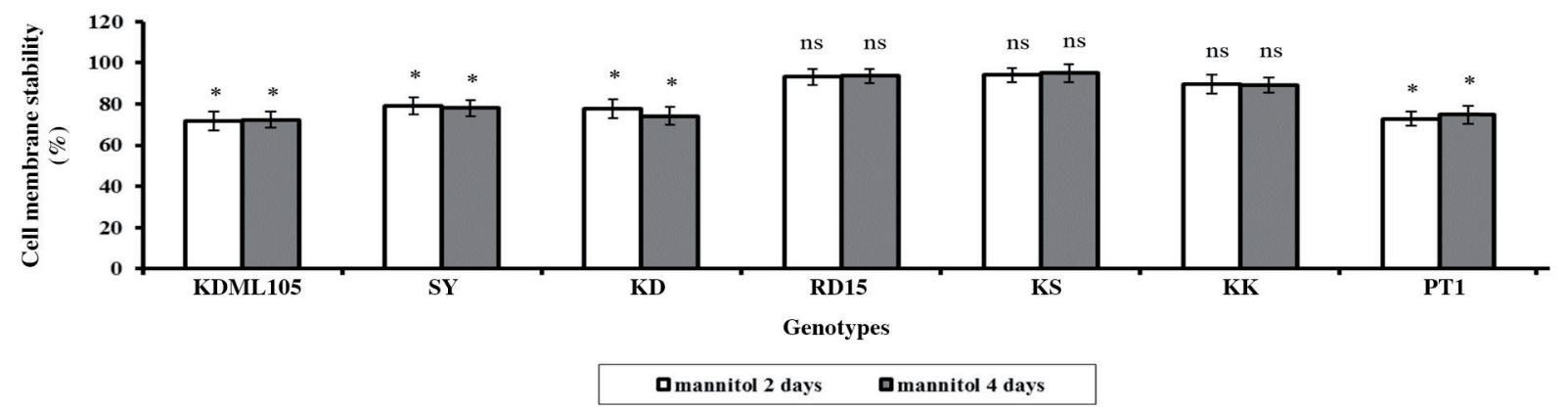

Values are percentage means \pm SD.

*Significant at the 0.05 probability level.

ns: Nonsignificant difference.

genotypes under drought stress was $20.86 \%$ to $28.14 \%$ compared with control plants, indicating that stressed seedlings from the RD15, KS, and KK genotypes have a greater ability to endure drought stress.

Drought stress significantly decreased the relative growth rate and cell membrane stability of drought-stressed plants. These results showed that a decrease in the relative growth rate was associated with impaired cell membrane stability in stressed seedlings (Figures 1 and 2). Indica rice genotypes RD15, KS, and KK showed a significantly lower decrease in the relative growth rate and cell membrane stability than genotypes KDML105, SY, KD, and PT1 under drought stress, which reflects the tolerance trait of the RD15, KS, and KK genotypes and sensitivity trait in the KDML105, SY, KD, and PT1 genotypes.

Drought stress also induces the evident accumulation of free radicals and causes oxidative burst in plant cells. The antioxidant enzyme activity is simultaneously activated to eliminate the ROS. Results showed a significant increase in SOD, CAT, and POD activity (Figure 3). Overall, increased

Figure 3. Specific enzyme activity of superoxide dismutase enzyme (SOD) (A), catalase (CAT) (B) and peroxidase (POD) (C) of unstressed and stressed seedlings grown in a photoautotrophic system under drought stress (100 mM mannitol).
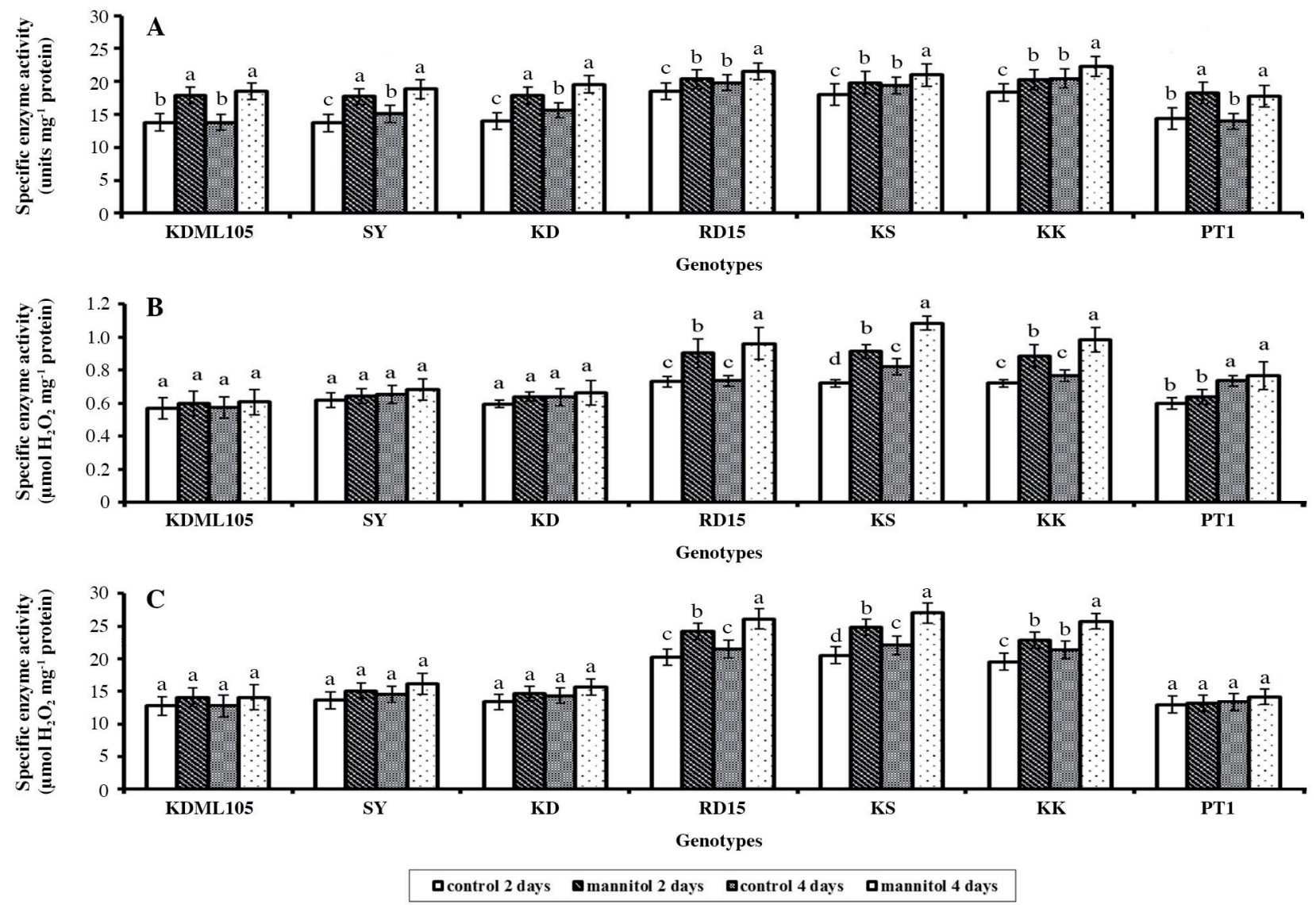

Values are means $\pm \mathrm{SD}$.

Different letters for the same genotype are significantly different $(P \leq 0.05)$. 
activity in all the antioxidant enzymes was induced in all the genotypes under drought stress compared with the unstressed seedlings.

Antioxidant enzyme activity, such as SOD, CAT, and POD, increased significantly in both genotype groups under stress. Drought tolerance or genotype sensitivity were correlated with antioxidant enzyme responses. In drought-sensitive genotypes, the drought treatment caused an approximate increase of $24.84 \%$ to $33.99 \%$ in total SOD activity compared with control plants; this was higher than the rate increase in drought-tolerant genotypes (7.90\% to $10.74 \%$ ) (Figure 3A). The CAT and POD activity of drought-tolerant seedlings, approximately $22.99 \%$ to $32.05 \%$ and $16.86 \%$ to $22.33 \%$, respectively, had a higher rate increase than drought-sensitive seedlings compared with control seedlings (Figures 3B and $3 \mathrm{C}$ ). The mean rate increase in CAT and POD activity of drought-sensitive seedlings was approximately $4.02 \%$ to $7.40 \%$ and $1.39 \%$ to $10.70 \%$, respectively.

Figure 4 describes free radical scavenging in the unstressed and stressed seedling extracts. Scavenging of ABTS and DPPH radicals is a potent tool to establish the total antioxidant capacity of an extract. The extract contained 1.14-3.03 $\mu \mathrm{M}$ Trolox $\mathrm{g}^{-1} \mathrm{FW}$ of the total antioxidant capacity expressed as the TEAC (Figure 4A). In these drought-tolerant genotypes, TEAC contents were found to be 1.92 to 2.63 -fold higher than control seedlings; this increase was higher than the TEAC contents in droughtsensitive genotype extracts (1.20 to 1.26-fold).

The $\mathrm{EC}_{50}$ value is a widely used parameter to measure antioxidant activity and a lower value is correlated with higher antioxidant capacity of crude extract. The $\mathrm{EC}_{50}$ values of unstressed and unstressed seedling extracts are shown in Figure 4B. The $\mathrm{EC}_{50}$ value of the stressed seedling extracts ranged from 524.12 to $747.20 \mu \mathrm{L} \mathrm{g}^{-1} \mathrm{FW}$, and it had a lower capacity than the unstressed seedling extract from their genotypes ( 0.84 to 0.97 -fold). For the group of drought-tolerant genotypes, the decrease in the $\mathrm{EC}_{50}$ value ( 0.84 to 0.87 -fold) was higher than the decrease in the $\mathrm{EC}_{50}$ value ( 0.94 to 0.97 -fold) of seedling extracts from droughtsensitive genotypes. These results indicated that the extract from drought-tolerant genotypes had greater antioxidant capacity than the extract from drought-sensitive genotypes.

The change in the relative growth rate and cell membrane stability was investigated in correlation with the change in antioxidant enzyme activity and total antioxidant capacity (Table 1). The correlation coefficient $\left(\mathrm{R}^{2}\right)$ between the relative growth rate with CAT $\left(\mathrm{R}^{2}=0.99\right)$ and POD $\left(\mathrm{R}^{2}=\right.$

Table 1. Correlation coefficient $\left(\mathbf{R}^{2}\right)$ between percentages of superoxide dismutase (SOD), catalase (CAT), and peroxidase (POD) enzyme activity, total antioxidant capacity using ABTS assay and total antioxidant capacity using DPPH assay and relative growth rate and cell membrane stability percentages from stressed seedlings grown in a photoautotrophic system under drought stress (100 mM mannitol).

\begin{tabular}{lcc}
\hline Enzymes & Relative growth rate & Cell membrane stability \\
\cline { 2 - 3 } SOD & -0.90 & -0.92 \\
POD & +0.96 & +0.90 \\
CAT & +0.80 & +0.86 \\
ABTS assay & +0.91 & +0.89 \\
DPPH assay & -0.96 & -0.90 \\
\hline
\end{tabular}

$(+)$ positive correlation.

(-) negative correlation.

ABTS: 2,2'-Azino-bis[3-ethylbenzothiazoline-6-sulfonic acid] diammonium salt.

DPPH: 2,2-Diphenyl-1-picrylhydrazyl.

Figure 4. Total antioxidant capacity expressed as Trolox equivalent antioxidant capacity (TEAC) (A) and half of the maximal effective concentration $\left(\mathbf{E C}_{50}\right)(\mathrm{B})$ using the ABTS and DPPH assays of unstressed and stressed seedlings grown in a photoautotrophic system under drought stress (100 mM mannitol).
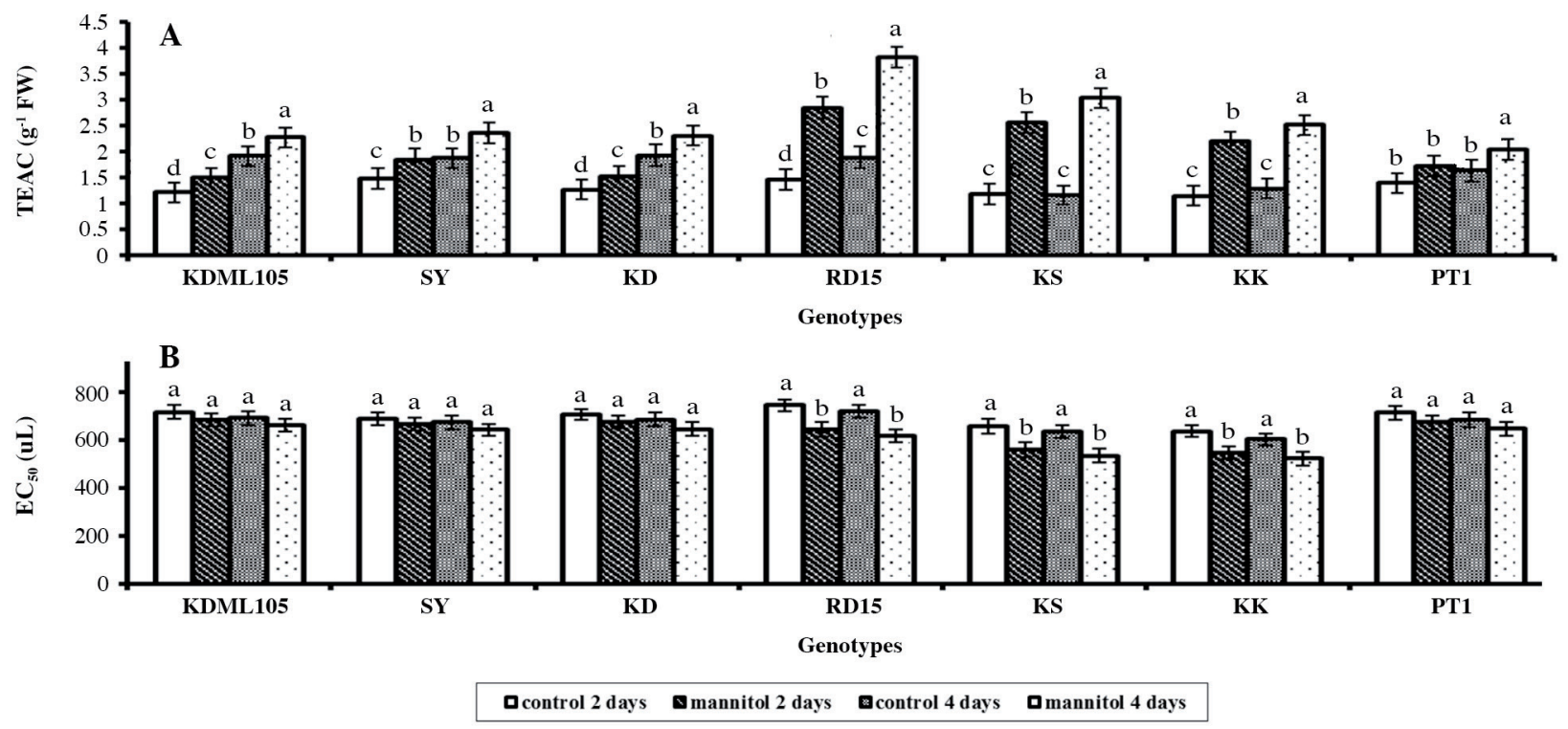

Values are means $\pm \mathrm{SD}$

Different letters for the same genotype are significantly different $(P \leq 0.05)$.

ABTS: 2,2'-Azino-bis[3-ethylbenzothiazoline-6-sulfonic acid] diammonium salt.

DPPH: 2,2-Diphenyl-1-picrylhydrazyl). 
$0.93)$ enzyme activity and TEAC values $\left(R^{2}=0.96\right)$ was significantly positive. However, $\mathrm{R}^{2}$ between the relative growth rate with SOD $\left(\mathrm{R}^{2}=0.93\right)$ enzyme activity and $\mathrm{EC}_{50}$ values $\left(R^{2}=0.97\right)$ was significantly negative (Table 1$)$.

The change in cell membrane stability with CAT and POD enzyme activity and TEAC values was positively correlated (Table 1). The $\mathrm{R}^{2}$ values were $0.95,0.92$, and 0.91 for CAT and POD enzyme activity and TEAC values, respectively. In contrast, $\mathrm{R}^{2}$ values for cell membrane stability with SOD activity and $\mathrm{EC}_{50}$ values were 0.94 and 0.96 , respectively, which showed a negative correlation (Table 1). The results suggested that the accumulation of CAT and POD activity, as well as total antioxidant capacity of the seedling extracts significantly contributed to protecting stressed seedlings.

\section{DISCUSSION}

Plants have developed several mechanisms to manage the damaging effects of abiotic stresses. The initial plant morphological response to drought stress is the growth rate. Reduced growth may be an adaptive response to abiotic stress (Junjittakarn et al., 2014). Plant growth is one parameter in the drought-sensitive morphological processes caused by the decreased turgor pressure during drought stress (Misra et al., 2002; Inostroza et al., 2015). This growth response seems to indicate that the degree of tolerance to drought stress of the rice genotypes under study was compared with the growth response reported for other plants subjected to drought or water deficit conditions. In general, plant genotypes protect themselves from droughtinduced oxidative stress by maintaining a higher growth rate and membrane stability, which indicate more tolerant genotypes (Yang et al., 2008).

The first organelle affected by various stresses is the cell membrane. Plant cell membranes are subjected to changes associated with ion leakage enhancement and cell integrity disadvantage under stress conditions. Drought stress that induces free radical formation causes lipid peroxidation and, therefore, membrane injury and degradation. Cell membrane stability is one of the main parameters for cellular responses under drought conditions and the abiotic tolerance factor in crop plants. Lower cell membrane stability in sensitive genotypes compared with tolerant genotypes has also been reported (Liu et al., 2008). Cell membrane stability, as a membrane integrity index, decreased under drought conditions. It was reported that membrane permeability in wheat (Huseynova, 2012), strawberry (Ghaderi and Siosemardeh, 2011), and marigold (Tian et al., 2012) increased under drought conditions with increasing levels of stress sensitivity.

Drought stress can lead to water deficiency, which induces stomatal closure following the reduction and availability of $\mathrm{CO}_{2}$ and inhibits $\mathrm{C}$ fixation by overly reducing the electron transport chain. This situation could increase the generation of ROS and influence oxidative damage. Increased ROS production in chloroplasts, mitochondria, and peroxisomes under drought stress has been described (Demirevska et al., 2008). The accumulation of ROS depends on the balance between ROS scavenging and ROS formation under stress conditions. The degree of antioxidant enzyme activity and the amount of nonenzymatic antioxidants have varied patterns among different plant species and stresses, stress duration, stress intensity, and plant development stage. An increase in antioxidant enzyme activity under abiotic stresses could indicate ROS production and the establishment of a protective mechanism to diminish exposure to oxidative damage in plant cells (Jaleel et al., 2009).

Tolerant plant genotypes usually have a better antioxidant system content to protect them from oxidative stress by maintaining high antioxidant enzyme and antioxidant molecule activity and contents under stress conditions (Chang-Quan and Rui-Chang, 2008). The SOD, CAT, and POD are key antioxidant enzymes in the plant cell. Many studies demonstrated that these enzymes had high activity during a water deficit stage and the defense mechanism competed against ROS formation (Tahi et al., 2008; Carrasco-Ríos and Pinto, 2014).

Among the enzymatic mechanisms, the first step in ROS scavenging catalyzes the rapid decrease of superoxide radicals into $\mathrm{H}_{2} \mathrm{O}_{2}$ by SOD. The CAT and POD then catalyze $\mathrm{H}_{2} \mathrm{O}_{2}$ into $\mathrm{H}_{2} \mathrm{O}$ to protect the plant cell from $\mathrm{H}_{2} \mathrm{O}_{2}$ accumulation (Simova-Stoilova et al., 2008; Carrasco-Ríos and Pinto, 2014). The bulk of $\mathrm{H}_{2} \mathrm{O}_{2}$ from SOD catalyzation remained biologically toxic. Therefore, SOD can limit plant protection from ROS because the increased rate of SOD activity in drought-tolerant genotypes was lower than in drought-sensitive genotypes. The production of $\mathrm{H}_{2} \mathrm{O}_{2}$ due to activated SOD enzymes can function in oxidative stress signaling and play the role of a secondary messenger to protect reactions leading to induced CAT and POD activity in plants (Anjum et al., 2011). Results revealed that the low increase of CAT and POD activity in drought-sensitive genotypes could reduce plant cell efficiency to scavenge damaging free radicals. This research study suggested that most of the antioxidant activity had an important role in stress tolerance. Therefore, the high stability and increased rate of CAT and POD activity may be known to confer drought-induced oxidative stress tolerance (Tian et al., 2012).

Currently, applying ABTS and DPPH to measure a free radical for plant sample screening have been investigated in stress tolerance (Cui et al., 2010). The high increment in both ABTS and DPPH radical scavenging capacity also appeared to be correlated with the degree of plant seedling stress tolerance (Weidner et al., 2009; Dominguez-Perles et al., 2011). Evaluations of drought tolerance have been investigated as the reduction of the growth rate and cell membrane stability, which were differentiated among plant genotypes and correlated with enzymatic and nonenzymatic antioxidants (Sharifi et al., 2012).

Since antioxidant capacity can be directly correlated to drought tolerance, the level of TEAC and $\mathrm{EC}_{50}$ values 
obtained in ABTS and DPPH assays indicated that it has high antioxidant capacity. Moreover, the observed correlation between CAT and POD activity and the relative growth rate and cell membrane stability emphasized the importance of maintaining an optimum content under the stress conditions to the degree of drought tolerance. Drought-tolerant plants generally have a great antioxidant system capacity that increased various times over the unstressed plants compared with drought-sensitive plants in response to stress conditions (Kolarovic et al., 2009). These were considered as significant physiological parameters of drought tolerance in plants. The above data demonstrated that the ROS scavenging system was a necessary component of the defense mechanism as opposed to drought stress in plant cells.

\section{CONCLUSIONS}

The higher relative growth rate level, cell membrane stability, constitutive catalase and peroxidase activity, and total antioxidant capacity in the drought-induced rice seedlings indicated that drought-tolerant genotypes had a high free radical degradation content. These results collectively suggested that the knowledge of these parameters in responses to drought stress may be further applied as criteria to drought-tolerant screening in indica rice genotypes or other plant species.

\section{ACKNOWLEDGEMENTS}

This research was kindly supported by grant KREF015401 from King Mongkut's Institute of Technology Ladkrabang Research Fund. The author is grateful to Pathumthani Rice Research Center, Udon Thani, and Roiet Rice Seed Center for providing rice seeds.

\section{REFERENCES}

Aebi, H. 1984. Catalase in vitro. Methods in Enzymology 105:121126. doi:10.1016/S0076-6879(84)05016-3.

Anjum, S.A., X.Y. Xie, L.C. Wang, M.F. Saleem, C. Man, and W. Lei. 2011. Morphological, physiological and biochemical responses of plants to drought stress. African Journal of Agricultural Research 6:2026-2032. doi:10.5897/AJAR10.027.

Beffa, R., H.V. Martin, and P.E. Pilet. 1990. In vitro oxidation of indoleacetic acid by soluble auxin-oxidases and peroxidases from maize root. Plant Physiology 94:485-491. doi:10.1104/ pp.94.2.485.

Beuchamp, C., and I. Fridovich. 1971. Superoxide dismutase: improved assays and an assay applicable to acrylamide gels. Analytical Biochemistry 44:276-287. doi:10.1016/00032697(71)90370-8.

Bradford, M.M. 1976. A rapid and sensitive method for the quantitation of microgram quantities of protein utilizing the principle of protein-dye-binding. Analytical Biochemistry 72:248-254. doi:10.1016/0003-2697(76)90527-3.
Brand-Williams, W., M.E. Cuvelier, and C. Berset. 1995. Use of a free radical method to evaluate antioxidant activity. LWTFood Science and Technology 28:25-30. doi:10.1016/S00236438(95)80008-5.

Carrasco-Ríos, L., and M. Pinto. 2014. Effect of salt stress on antioxidant enzymes and lipid peroxidation in leaves in two contrasting corn, 'Lluteño' and 'Jubilee'. Chilean Journal of Agricultural Research 74:89-95. doi:10.4067/S071858392014000100014.

Chang-Quan, W., and L. Rui-Chang. 2008. Enhancement of superoxide dismutase activity in the leaves of white-clover (Trifolim repens L.) in response to polyethylene glycolinduced water stress. Acta Physiologiae Plantarum 30:841-847. doi:10.1007/s11738-008-0189-8.

Cheng, Y.J., X.P. Deng, S.S. Kwak, W. Chen, and A.E. Eneji. 2013. Enhanced tolerance of transgenic potato plants expressing choline oxidase in chloroplasts against water stress. Botanical Studies 54:30-38. doi:10.1186/1999-3110-54-30.

Cui, X.H., H.N. Murthy, C.H. Wu, and K.Y. Paek. 2010. Sucroseinduced osmotic stress affects biomass, metabolite, and antioxidant levels in root suspension cultures of Hypericum perforatum L. Plant Cell, Tissue and Organ Culture 103:7-14. doi:10.1007/s11240-010-9747-z.

Demirevska, K., L. Simova-Stoilova, V. Vassileva, and U. Feller. 2008. Rubisco and some chaperone protein responses to water stress and rewatering at early seedling growth of drought sensitive and tolerant wheat varieties. Plant Growth Regulation 56:97-106. doi:10.1007/s10725-008-9288-1.

Dominguez-Perles, R., M.C. Martinez-Ballesta, F. Riquelme, M. Carvajal, C. Garcia-Viguera, and D.A. Moreno. 2011. Novel varieties of broccoli for optimal bioactive components under saline stress. Journal of the Science of Food and Agriculture 91:1638-1647. doi:10.1002/jsfa.4360.

Fu, G.F., J. Song, J. Xiong, Y.R. Li, H.Z. Chen, M.K. Le, et al. 2011. Changes of oxidative stress and soluble sugar in anthers involve in rice pollen abortion under drought stress. Agricultural Sciences in China 10:1016-1025. doi:10.1016/S16712927(11)60089-8.

Ghaderi, N., and A. Siosemardeh. 2011. Response to drought stress of two strawberry cultivars (cv. Kurdistan and Selva). Horticulture, Environment, and Biotechnology 52:6-12. doi:10.1007/s13580-011-0019-6.

Hameed, A., N. Bibi, J. Akhter, and N. Iqbal. 2011. Differential changes in antioxidants, proteases, and lipid peroxidation in flag leaves of wheat genotypes under different levels of water deficit conditions. Plant Physiology and Biochemistry 49:178-185. doi:10.1016/j.plaphy.2010.11.009.

Huseynova, I.M. 2012. Photosynthetic characteristics and enzymatic antioxidant capacity of leaves from wheat cultivars exposed to drought. Biochimica et Biophysica Acta 1817:15161523. doi:10.1016/j.bbabio.2012.02.037.

Inostroza, L., H. Acuña, and G. Tapia. 2015. Relationships between phenotypic variation in osmotic adjustment, wateruse efficiency, and drought tolerance of seven cultivars of Lotus corniculatus L. Chilean Journal of Agricultural Research 75:3-12. doi:10.4067/S0718-58392015000100001.

Jaleel, C.A., K. Riadh, R. Gopi, P. Manivannan, J. Inès, H.J. Al-Juburi, et al. 2009. Antioxidant defense responses: physiological plasticity in higher plants under abiotic constraints. Acta Physiologiae Plantarum 31:427-436. doi:10.1007/s11738-009-0275-6. 
Junjittakarn, J., T. Girdthai, S. Jogloy, N. Vorasoot, and A. Patanothai. 2014. Response of root characteristics and yield in peanut under terminal drought condition. Chilean Journal of Agricultural Research 74:249-256. doi:10.4067/S071858392014000300001.

Kolarovic, L., P. Valentovic, M. Luxová, and O. Gasparíková. 2009. Changes in antioxidants and cell damage in heterotrophic maize seedlings differing in drought sensitivity after exposure to short-term osmotic stress. Plant Growth Regulation 59:21-26. doi:10.1007/s 10725-009-9384-x.

Li, L., R. Qu, A. De Kochko, C. Frauquet, and R.N. Beachy. 1993. An improved rice transformation method using the biolistic method. Plant Cell Reports 12:250-255. doi:10.1007/ BF00237129.

Liu, C.H., Y.Y. Chao, and C.H. Kao. 2013. Effect of potassium deficiency on antioxidant status and cadmium toxicity in rice seedlings. Botanical Studies 54:2-11. doi:10.1186/19993110-54-2.

Liu, J., X. Xie, J. Du, J. Sun, and X. Bai. 2008. Effects of simultaneous drought and heat stress on Kentucky bluegrass. Scientia Horticulturae 115:190-195. doi:10.1016/ j.scienta.2007.08.003.

Misra, A.N., A.K. Biswal, and M. Misra. 2002. Physiological, biochemical and molecular aspects of water stress responses in plants, and the biotechnological applications. Proceedings of the National Academy of Sciences, India - Section B: Biological Sciences 72:115-134.

Noggle, G.R., and G.J. Friz. 1976. Introductory plant physiology. Prentice-Hall, Englewood Cliffs, New Jersey, USA.

Re, R., N. Pellegrini, A. Proteggente, A. Pannala, M. Yang, and C. Rice-Evans. 1999. Antioxidant activity applying an improved ABTS radical cation decolorization assay. Free Radical Biology and Medicine 26:1231-1237. doi:10.1016/S08915849(98)00315-3

Sharifi, P., R. Amirnia, E. Majidi, H. Hadi, M. Roustaii, B. Nakhoda, et al. 2012. Relationship between drought stress and some antioxidant enzymes with cell membrane and chlorophyll stability in wheat lines. African Journal of Microbiology Research 6:617-623. doi:10.5897/AJMR11.1167.

Shukla, N., R.P. Awasthi, L. Rawat, and J. Kumar. 2012. Biochemical and physiological responses of rice (Oryza sativa L.) as influenced by Trichoderma harzianum under drought stress. Plant Physiology and Biochemistry 54:78-88. doi:10.1016/j.plaphy.2012.02.001.
Simova-Stoilova, L., K. Demirevska, T. Petrova, N. Tsenov, and U. Feller. 2008. Antioxidative protection in wheat varieties under severe recoverable drought at seedling stage. Plant, Soil and Environment 54:529-536. doi:10.1127/0340269X/2008/0038-0023.

Tahi, H., S. Wahbi, C. El Modafar, A. Aganchich, and R. Serraj. 2008. Changes in antioxidant activities and phenol content in tomato plants subjected to partial root drying and regulated deficit irrigation. Plant Biosystems 142:550-562. doi:10.1080/11263500802410900.

Tian, Z., F. Wang, W. Zhang, C. Liu, and X. Zhao. 2012. Antioxidant mechanism and lipid peroxidation patterns in leaves and petals of marigold in response to drought stress. Horticulture, Environment, and Biotechnology 53:183-192. doi:10.1007/s13580-012-0069-4.

Uzilday, B., I. Turkan, A.H. Sekmen, R. Ozgur, and H.C. Karakaya. 2012. Comparison of ROS formation and antioxidant enzymes in Cleome gynandra $\left(\mathrm{C}_{4}\right)$ and Cleome spinosa $\left(\mathrm{C}_{3}\right)$ under drought stress. Plant Science 182:59-70. doi:10.1016/ j.plantsci.2011.03.015

Weidner, S., E. Kordala, W. Brosowska-Arendt, M. Karamac, A. Kosinska, and R. Amarowicz. 2009. Phenolic compounds and properties of antioxidants in grapevine roots (Vitis vinifera L.) under low-temperature stress followed by recovery. Acta Societatis Botanicorum Poloniae 78:279-286. doi:10.5586/ asbp.2009.036

Yan, B., Q. Dai, X. Liu, S. Huang, and Z. Wang. 1996. Floodinginduced membrane damage, lipid oxidation and activated oxygen generation in corn leaves. Plant and Soil 179:261-268. doi:10.1007/BF00009336.

Yang, Y., C. Han, Q. Liu, B. Lin, and J. Wang. 2008. Effect of drought and low light on growth and enzymatic antioxidant system of Picea asperata seedlings. Acta Physiologiae Plantarum 30:433-440. doi:10.1007/s11738-008-0140-z.

Zhou, Y., J. Zhou, L. Huang, X. Ding, K. Shi, and J. Yo. 2009. Grafting of Cucumis sativus onto Cucurbita ficifolia leads to improve plant growth, increased light utilization and reduced accumulation of reactive oxygen species in chilled plants. Journal of Plant Research 122:529-540. doi:10.1007/s10265009-0247-3 